http://jmscr.igmpublication.org/home/ ISSN (e)-2347-176x ISSN (p) 2455-0450 crossref DOI: https://dx.doi.org/10.18535/jmscr/v9i1.01

Journal Of Medical Science And Clinical Research

\title{
Effect of Back Massage on Lactation among Postnatal Mothers in Tertiary Level Hospital
}

\author{
Authors \\ Dr Aditya Kushwah ${ }^{1}$, Dr Jolly G Vaishnav², Dr Arif S Vohra ${ }^{3}$, Dr Priyanka Mistry ${ }^{1}$ \\ ${ }^{1}$ Resident doctor Department of Paediatrics \\ ${ }^{2}$ Professor and Head of Department of Paediatrics \\ ${ }^{3}$ Assistant Professor Department of Paediatrics \\ B.J. Medical College, Ahmedabad, Gujarat, India
}

\begin{abstract}
Introduction: Breastfeeding is an important tool for reducing infant mortality in developing countries like India. The present study was an attempt at identifying the effectiveness of a simple, easily adaptable and public health system friendly methods apart from conventionally used methods to promote lactation among postpartum mothers. In India, back massage had been practised in many cultures/societies to promote/sustain breastfeeding.

Methods: A case control study was performed at postnatal ward of a tertiary level hospital, with aiming to study the effect of back massage on lactation among postnatal mothers. During the study total 100 mothers of postnatal wards were included which were randomly divided into two groups: group $\boldsymbol{A}(N=50)-$ mothers who has received back massage in first three postnatal days and group $\boldsymbol{B}(N=50)$-mothers who had not received back massage. The study was carried out in mothers of healthy full term appropriate for gestational age neonates which were born to primi mothers without medical illness or breast abnormalities, vaginally delivered and had normal feeding reflexes. The massage was started on mothers and its effect on various parameters like post feed weight gain, sleep duration, number of urine and stools passed per day etc were assessed.

Results: There was significantly higher mean post feed weight gain, mean number of urine and stool passed per day and mean duration of sleep in back massage group than control group.

Conclusion: The back massage is effective in improving the lactation among postnatal mother. Back massage is specifically can be used in postnatal mothers who are facing the problems in initiating and sustaining breastfeeding

Keywords: Back massage, Lactation, Breast milk, letdown reflex, lactation failure, postnatal mothers, exclusive breastfeeding.
\end{abstract}

\section{Introduction}

Lactation is affected by a large number of factors such as mode of delivery, labour experience, illness, anxiety, stress, breast and nipple abnormality, body mass index, smoking, surgery etc ${ }^{[1-4]}$. Even mild stress can negatively affect the lactation $^{5}$. Psychological stress, resulting from pain and fatigue after labour, lack of support to mother and difficulties encountered on initiation of breastfeeding causes neuroendocrine dysregulation leading to irregularities in hypothalamo pituitary adrenal axis function leading to delayed onset and insufficient milk production $^{6}$. On the other hand, motivation for 
breastfeeding, providing social support, counselling for promotion of breastfeeding, good nursing support and good breast-feeding experiences are other positive factors for lactation $^{1}$.

The present study was an attempt at identifying the effectiveness of a simple, easily adaptable and public health system friendly methods apart from conventionally used methods like use of galactagogues, placebos and nutritional supplements to promote lactation among postpartum mothers. In India, back massage had been practised in many cultures/societies to promote/sustain breastfeeding ${ }^{1}$.For many years, China has used acupressure, also called shiatsu, to increase lactation ${ }^{7}$.Compared to other nonpharmacologic measures used for stimulating lactation like acupuncture ${ }^{8}$ and infrared radiation, back massage is by far much simpler and practical in our setups. So, we hypothesize that back massage should help decrease stress and anxiety of new mothers and help in stimulating lactation. To test this hypothesis, we conducted an experimental study at tertiary level hospital aimed to assess the effect of back massage on lactation.

\section{Materials and Methods}

A case control study was performed at postnatal ward of civil hospital Ahmedabad, Gujarat over duration of $1^{\text {st }}$ December 2018 to $28^{\text {th }}$ February 2019 with aiming to study the effect of back massage on lactation among postnatal mothers. During the study period total 100 mothers of postnatal wards were included which were randomly divided into two groups: group A mothers who has received back massage in first three postnatal days and group B -mothers who had not received back massage.

Inclusion Criteria: The study was carried out in mothers of full term appropriate for gestational age neonates which were born to primi mothers, vaginally delivered and had normal feeding reflexes.

Exclusion Criteria: Neonates who were premature, having congenital anomalies or any neurological conditions leading to poor feeding reflexes were excluded. Also, mothers having nipple or breast abnormalities or attachment difficulties, having any medical illness or having medications affecting lactation or breastfeeding were excluded.

In Group A mothers, the first back massage was given within 2 hours of delivery and continued for 4 times a day at regular intervals for three days. This was applied for $15 \mathrm{~min}$ at each sitting. Massage was performed by healthcare personnel. First, the steps of the procedure were explained to subjects. After proper exposure and comfortable position, gentle pressure with both thumbs was given on the back at the lateral sides of spine in circulatory motion. Movements were given "to" and "fro" from neck to buttocks and back to neck. Just after massage, fullness of breast was assessed and baby was given to mother for feeding. In group B, mothers did not receive any massage treatment. However, similarly fullness of breast was also assessed in them and their baby was given to them for feeding.

In both the groups, pre feed and post feed weights were assessed. Babies were weighed naked on Conweigh electronic weighing scale, available in ward, having error of \pm 5 gms. Over the next 3 days, other parameters like post feed weight gain, number of urinations ${ }^{9}$ and number of stools passed per day, duration of sleep in hours after breast feeding, satiety of baby at the end of breast feeding and need for supplementary feed, were also assessed and recorded in proforma.

\section{Observations and Discussion}

The base line characteristics of study population are described in Table 1. The baseline characteristics of mother of the neonates viz. Mean maternal weight, mean maternal haemoglobin at admission and mean maternal age of both the groups were statistically not significant and thus both the groups were comparable. Similarly, the mean birth weight of neonates and mean sex ratio of neonates were comparable in both the groups. 
Table 1

\begin{tabular}{|l|c|c|c|}
\hline Parameter & $\begin{array}{c}\text { Group A } \\
(\mathrm{n}=50)\end{array}$ & $\begin{array}{c}\text { Group B } \\
(\mathrm{n}=50)\end{array}$ & P value \\
\hline Mean Maternal Weight & $59.87 \pm 7.75 \mathrm{~kg}$ & $56.58 \pm 9.75 \mathrm{~kg}$ & 0.06 \\
\hline Mean Maternal Haemoglobin & $9.27 \pm 1.37 \mathrm{~g} / \mathrm{dl}$ & $9.61 \pm 1.30 \mathrm{~g} / \mathrm{dl}$ & 0.20 \\
\hline Mean Maternal Age & $22.6 \pm 3.36$ years & $21.69 \pm 5.92$ years & 0.35 \\
\hline Mean Birth Weight & $2.89 \pm 0.33 \mathrm{~kg}$ & $2.95 \pm 0.39 \mathrm{~kg}$ & 0.41 \\
\hline Mean sex ratio of neonates & 3.16 & 2.68 & 0.65 \\
\hline
\end{tabular}

As shown in table 2, it was observed that the difference of Mean post feed weight gain on day 1 was statistically not significant in both the groups but the mean post feed weight gain over day 2 and day 3 was observed statistically significant higher in group A as compared to group B with p value 0.03 and 0.04 respectively at df 98 and alpha $<0.05$ values. The cumulative mean post feed weight gain was higher in Group A $(2.2 \pm 0.59$ $\mathrm{g} / \mathrm{kg} /$ day) as compared to Group B $(1.4 \pm 0.64$ $\mathrm{g} / \mathrm{kg} /$ day) with $\mathrm{p}$ value $<0.05$ as shown in table 2 below.

The mean duration of sleep after breastfeeding over three days in group A was 50.79+4.36 hours and in group B was $43.62 \pm 4.1$ hours per day which is found statistically significant at $p$ value $<0.05$, so more duration of sleep was observed in back massage group as compare to control group. Statistically significant ( $\mathrm{p}$ value $<0.05$ ) difference was noted in mean number of passage of stools over 3 days in group A as compare to group B; but no difference ( $p$ value 0.27 ) was noted in passage of urine over 3 days in both the groups.

At the end of day 3, none of baby in back massage group required supplementary feed, while $6 \%$ of babies in control group require supplementary feed which was statistically non-significant ( $p$ value 0.08 ).

\section{Table 2}

\begin{tabular}{|c|c|c|c|c|}
\hline \multicolumn{2}{|l|}{ Parameter } & $\begin{array}{c}\text { Group A }(\mathrm{N}=50) \\
\text { Back massage group }\end{array}$ & $\begin{array}{l}\text { Group } B(\mathrm{~N}=50) \\
\text { Control group }\end{array}$ & $\mathrm{p}$ value \\
\hline \multicolumn{2}{|l|}{ Mean post feed weight gain(g/kg/day) } & $2.2 \pm 0.59$ & $1.4 \pm 0.64$ & 0.001 \\
\hline \multirow[t]{3}{*}{ Mean post feed weight gain(g/day) } & Day 1 & $10 . \overline{4} \pm 1.73$ & $10.02+1.73$ & 0.27 \\
\hline & Day2 & $21.56 \pm 2.93$ & $18.28 \pm 4.73$ & 0.001 \\
\hline & Day3 & $38.84 \pm 3.54$ & $26.58 \pm 6.93$ & 0.0001 \\
\hline $\begin{array}{l}\text { Mean duration of sleep afte } \\
\text { (minutes/day) }\end{array}$ & Breastfeed & $50.79 \pm 4.36$ & $43.62+4.1$ & 0.0001 \\
\hline \multicolumn{2}{|l|}{ Mean number of times stool passed } & $3.29 \pm 1.86$ & $2.5 \pm 1.12$ & 0.016 \\
\hline \multicolumn{2}{|c|}{ Mean number of times urine passed } & $5.15 \pm 1.95$ & $5.33 \pm 1.52$ & 0.61 \\
\hline \multicolumn{2}{|c|}{$\begin{array}{l}\text { Requirement of top feed (Number of newborn) on } \\
\text { fourth day }\end{array}$} & $0 \%$ & $6 \%$ & 0.08 \\
\hline
\end{tabular}

Breastfeeding is a best gift to a newborn from the mother after birth ${ }^{10}$. WHO, UNICEF and IAP recommend exclusive breastfeeding for first six months of life and breastfeeding upto 2 years of life $^{11}$. It is important tool for reducing infant mortality in developing countries like India. The national family health survey-4(NFHS-4) published in 2015-16; only $41.5 \%$ of new mothers initiate breastfeeding in $1^{\text {st }}$ hour after birth, $21.1 \%$ children received prelacteal feed during first three days of life and only $55 \%$ were exclusively breast fed upto 6 months of age ${ }^{11}$. Most of the postpartum mothers especially primi mothers feel more anxious and stressed in initial days after birth due to insufficient lactation which will viciously suppress lactation further and more dependent on top milk which again add in lactation failure ${ }^{12}$.

In the first hours after giving birth, physiologically the hormone oxytocin and prolactin are released which are responsible for the smooth production of breast milk, where the 
hormone prolactin plays a role in the production of milk and the hormone oxytocin stimulates the release of milk. The release of oxytocin is influenced by the stimulation of baby's mouth suction, smell, sound or touch. It is also released when mother feels calm, stress free and relaxed. Back massage is a relaxation technique.The massage will stimulate the medulla oblongata to directly send a message to the hypothalamus in the posterior hypothalamus to release oxytocin, (the oxytocin or milk letdown reflex) which causes the breast to secrete milk and help mothers feel in reducing pain (Adams et al, 2010). ${ }^{12}$

After reviewing study and comparing results there was significant difference among both groups. The mean post feed weight gain is statistically significantly higher in study group which indicates that back massage has a positive effect on lactation ( $p$ value 0.05).Also, statistically significant ( $p$ value 0.05 ) more duration of sleep and satiety was observed in back massage group as compare to control group. Similar results were also obtained in individual studies done by Patel $\mathrm{U}$ et al, 2013 ${ }^{[10]}$ and Mrs Tika et al, 2016 ${ }^{[1]}$ and Jogdeo et al, 2013 ${ }^{[12]}$.

In our study, at the end of day 3 , none of baby in back massage group required supplementary feed, while $8 \%$ of babies in control group require supplementary feed which was statistically nonsignificant ( $p$ value 0.79 ).

Mean number of stools passed per day by the babies were higher in study group which again indicate improved lactation in study group. In our study, statistically significant ( $p$ value 0.01 ) difference was noted in mean number of passage of stools in group A as compare to group B; however no difference ( $p$ value 0.27 ) was noted in passage of urine. while in study by Patel $U$ et al, on first and second day $\mathrm{t}$ value did not show significant statistical difference between groups in regards to mean passage of urine and stool, but on third day it shows significant statistical difference at $<0.05$ level in between both groups in regard to passage of urine and stool. This indicates that urine and stool output is increased significantly in
Group A on third day; this indicates improving lactation in immediate postpartum mothers. In Mrs Tika et al,2016 ${ }^{[1]}$ and Widiastuti et al,2019 ${ }^{[13]}$ study more significant impact on mean passage of urine and stool frequency observed on first three days of life.

\section{Conclusion}

The back massage is effective in improving the lactation among postnatal mother. Back massage is specifically can be used in postnatal mothers who are facing the problems in initiating and sustaining breastfeeding. Back massage is simple, can be implemented using the existing healthcare personnel, without straining resources to achieve or increase exclusively breastfeeding in neonates.

\section{Acknowledgement:}

We are thankful to all our teachers and colleagues and our institution and staff members for helping us in every possible way. Big thanks to those neonates and mothers who made possible this study.

\section{Conflict of Interest: None}

\section{References}

1. Khanal Mrs.Tika Bhawani, Angeline et al, Effect of Back Massage on Lactation Among Postnatal Mothers in Postnatal Ward of Selected Hospital, Mangaluru. IJAR, Volume : 6 | Issue : $11 \mid$ November 2016 | ISSN - 2249-555X | IF : 3.919 | IC Value : 74.50

2. Grajeda R, Pérez-Escamilla R. Stress during labor and delivery is associated with delayed onset of lactation among urban Guatemalan women. J Nutr. 2002 Oct;132(10):3055-60.

3. Ueda T, Yokoyama Y, Irahara M, Aono T. Influence of psychological stress on suckling-induced pulsatile oxytocin release. Obstet Gynecol. 1994 Aug; 84 (2):259-62. 
4. Ruvalcaba RH. Stress-induced cessation of lactation. West J Med. 1987 Feb;146 (2):228-30. 5. Mathur GP, Chitranshi S, Mathur S, Singh SB, Bhalla M. Lactation failure. Indian Pediatr. 1992 Dec;29(12):1541-4.

5. Dewey KG. Maternal and fetal stress are associated with impaired lactogenesis in humans. J Nutr. 2001 Nov;131(11):3012S$5 \mathrm{~S}$.

6. K. Sakha, A.G.G. Behbahan. The onset Time of Lactation after Delivery. Medical Journal of The Islamic Republic of Iran. 2005; 19(2):135-39.

7. Wang HC, An JM, Han Y, Huang LN, Zhao JW, Wei LX, Dong L, Zhai GR, Li $\mathrm{XP}$, Yang AJ, Gu M. [Multicentral randomized controlled studies on acupuncture at Shaoze (SI 1) for treatment of postpartum hypolactation]. Zhongguo Zhen Jiu. 2007 Feb;27(2):85-8.

8. Lu P, Qiu J, Yao F, Zheng JJ. [Effect of acupoint Tuina on lactation amount for parturient]. Zhongguo Zhen Jiu. 2010 Sep;30(9):731-3

9. Nommsen-Rivers LA1, Heinig MJ, Cohen RJ, Dewey KG. Newborn wet and soiled diaper counts and timing of onset of lactation as indicators of breastfeeding inadequacy. J Hum Lact. 2008 Feb;24 (1): 27-33. doi: 10.1177/0890334407311538.

10. Patel U, Gedam DS, Verma M, effect of back massage on lactation among postnatal mothers. Int J Med Res Rev 2013;1(1):0511

11. National Family Health. Survey (NFHS4). 2015-16. Ministry of Health and family walfare. Available online at: www.nhm.gov.in>schemes>maa.

Accessed on 27/09/2020
12. Jogdeo B, BhoreN, et al, The Effect of Back Massage on Breast Feeding among Neonates who's Mothers Had Undergone Cesarean Section, International Journal of Science and Research (IJSR) ISSN (Online): Volume 5 Issue 4, April 2016 ,2319-7064 Index Copernicus Value (2013): 6.14 | Impact Factor (2013): 4.438

13. Widiastuti NMR et al, 2019, Improved breastfeeding with back massage among postnatal mothers ,* International Journal of Research in Medical Sciences. Int J Res Med Sci. 2020 Feb;8(2):580-583. 